Article

\title{
Effect of Cavity Structure on Acoustic Characteristics of Phononic Crystals Based on Double-Layer Plates
}

\author{
Chuanmin Chen ${ }^{1,2, *(\mathbb{D}}$, Zhaofeng Guo ${ }^{1,2}$, Songtao Liu ${ }^{1,2}$, Hongda Feng ${ }^{1,2}$ and Chuanxi Qiao ${ }^{1,2}$ \\ 1 Hebei Key Lab of Power Plant Flue Gas Multi-Pollutants Control, Department of Environmental Science and \\ Engineering, North China Electric Power University, Baoding 071003, China; \\ chnguozhaofeng@163.com (Z.G.); taonyliu@163.com (S.L.); hongdafeng1995@163.com (H.F.); \\ qiaochuanxi@163.com (C.Q.) \\ 2 MOE Key Laboratory of Resources and Environmental Systems Optimization, College of Environmental \\ Science and Engineering, North China Electric Power University, Beijing 102206, China \\ * Correspondence: 52350852@ncepu.edu.cn
}

Received: 23 September 2020; Accepted: 31 October 2020; Published: 3 November 2020

check for updates

\begin{abstract}
Localized resonance phononic crystals (LRPCs) are increasingly attracting scientists' attention in the field of low-frequency noise reduction because of the excellent subwavelength band gap characteristics in the low-frequency band. However, the LRPCs have always had the disadvantage that the noise reduction band is too narrow. In this paper, in order to solve this problem, LRPCs based on double-layer plates with cavity structures are designed. First, the energy bands of phononic crystals plate with different thicknesses were calculated by the finite element method (FEM). At the same time, the mechanism of band gap generation was analyzed in combination with the modalities. Additionally, the influence of structure on the sound transmission loss (STL) of the phononic crystals plate and the phononic crystals cavity plates were analyzed, which indicates that the phononic crystals cavity plates have notable characteristics and advantages. Moreover, this study reveals a unique "cavity cave" pattern in the STL diagram for the phononic crystals cavity plates, and it was analyzed. Finally, the influence of structural factors on the band structure and STL of phononic crystals cavity plates are summarized, and the theoretical basis and method guidance for the study of phononic crystals cavity plates are provided. New ideas are also provided for the future design and research of phononic crystals plate along with potential applications in low-frequency noise reduction.
\end{abstract}

Keywords: phononic crystals cavity plates; cavity structure; low frequency; noise reduction

\section{Introduction}

Reducing low-frequency noise has always been problematic. The primary reason for this is that the low-frequency sound waves penetrate the structure more easily than the high-frequency sound waves. The development of local resonance phononic crystals has resulted in the possibility of efficient low-frequency noise reduction [1-3]. The theoretical basis of phononic crystals was proposed by Sigalas and Economou [4] in 1992, which proved for the first time in theory that a solid spherical scattered projectile is embedded in a certain matrix material to form a three-dimensional periodic lattice structure with forbidden band elastic properties. In 1993, Kushwaha et al. [5] clearly proposed the concept of phononic crystals for the first time, and the composite medium formed by the nickel column in the aluminum alloy matrix is calculated by the plane wave method to obtain the elastic wave gap in the direction of shear polarization. A periodic material with an elastic-wave band gap is called a phononic crystals [6-9]. In 1995, when Martinez-Sala et al. [10] studied the acoustic characteristics of the sculpture "Flowing Melody" made more than 200 years ago in Madrid, Spain, they first determined the existence of elastic wave band gap from an experimental perspective. Liu introduced aluminum 
spheres into epoxy resin in 2000 and was the first to propose local-resonance-type phononic crystals of hetero-Bragg-scattering phononic crystals [11].

Local resonance phononic crystals have been increasingly researched in the field of noise reduction because they can suppress large-wavelength low-frequency sound waves through their small unit structure [12-14]. Research on phononic crystals has mainly focused on the effects of various materials and structures on the band gap of two-dimensional phononic crystals [15-20]; however, no structure with infinite z-axis size exists in the real world. Research on three-dimensional phononic crystals has gradually advanced to research on three-dimensional phononic crystals plate [3,21-23]. Many studies have examined the band gap of phononic crystals plate. However, for local resonance phonon crystals, except for the high sound transmission loss near the beginning of the band gap, the sound transmission loss (STL) in other frequency domains is very low. In order to widen the noise reduction band, scientists have made many efforts [24-29]. Dong et al. [25] investigated hybrid phononic crystals; the characteristic frequency of the xy mode, transmission loss, and displacement vector were calculated using the finite element method. A Bragg-scattering band gap and local resonance band gap were discovered to exist in the band structures. The band gap covers a large range at low frequencies. Below $3000 \mathrm{~Hz}$, the band gaps cover more than 95\% of the spectrum. Zhou et al. [26] found that the band gaps of locally resonant phononic crystals can be extended to several frequency ranges through periodic embedding of multilayered coaxial inclusions. The frequency response of multilayered periodic structures with various numbers of cells was simulated. However, the problem of too low STL outside the band gap starting point cannot be solved.

In order to solve this problem, we referenced the method of improving the noise reduction ability of traditional materials and applied it to the phononic crystals plate. The previous research indicates that a cavity structure significantly improves the sound insulation of ordinary single layer plate and makes a noise reduction material more lightweight [30-34]. Sarıgül et al. [35] calculated and presented a modal structural-acoustic coupling for plates with different composite parameters. The effects of material, ply angle, and number of layers on the coupled vibroacoustic characteristics of composite plate-cavity systems have been examined and compared with the behavior of isotropic plate systems. Xin et al. [36] investigated the vibroacoustic performance of a rectangular double-panel partition with an enclosed air cavity and simply mounted on an infinite acoustic rigid baffle. The simply supported boundary condition is accounted for by using the method of modal function, and the double Fourier series solutions are obtained to characterize the vibroacoustic behaviors of the structure. The results for sound transmission loss, panel vibration level, and sound pressure level are presented to explore the physical mechanisms of sound energy penetration across the finite double-panel partition. This paper proposes phononic crystals based on double-layer plates with a cavity structure. The noise reduction mechanism of phononic crystals cavity plate and the effect of the cavity structure on the STL of the phononic crystals based on double-layer plates are investigated by referring to previous research on cavity plate, and exploiting the unique band gap characteristics of phononic crystals. The present study of phononic crystals cavity plates provides a theoretical basis and methodological guidance. It also provides new ideas regarding the future design and research of phononic crystals plate and indicates potential applications in low-frequency noise reduction.

\section{Principle and Method of Band Structure}

To investigate the band structure characteristics of the proposed phononic crystals plate, band structures are calculated using the finite element method (FEM), proven in other work $[37,38]$ to constitute an efficient method.

The phononic crystal is first transformed from the real lattice vector space into the reciprocal lattice vector space by using the following equations:

$$
b_{1}=2 \pi \frac{a_{2} \times a_{3}}{a_{1} \cdot a_{2} \times a_{3}}
$$




$$
\begin{aligned}
& \boldsymbol{b}_{2}=2 \pi \frac{a_{1} \times a_{3}}{\boldsymbol{a}_{1} \cdot \boldsymbol{a}_{2} \times a_{3}} \\
& \boldsymbol{b}_{3}=2 \pi \frac{\boldsymbol{a}_{1} \times \boldsymbol{a}_{2}}{\boldsymbol{a}_{1} \cdot \boldsymbol{a}_{2} \times \boldsymbol{a}_{3}}
\end{aligned}
$$

where $\boldsymbol{a}_{i}$ and $\boldsymbol{b}_{i}$ are the axis vectors of the positive and reciprocal lattice vector spaces, respectively. By definition, the two axes of each inverted lattice and normal lattice are orthogonal, satisfying Equation (4):

$$
\boldsymbol{b}_{i} \cdot \boldsymbol{a}_{j}=2 \pi \delta_{i j}, \delta_{i j}=\left\{\begin{array}{l}
1, i=j \\
0, i \neq j
\end{array}\right.
$$

Because of the periodicity of the phononic crystals, the physical quantities in the real lattice and the changed inverted lattice meet the translation periodicity requirement, satisfying the following Equation:

$$
n(\boldsymbol{r})=\sum_{G} n(\boldsymbol{G}) e^{i G \cdot r}
$$

where $G$ is a reciprocal lattice vector space, which is a discretized vector space that satisfies the periodicity requirement in the Fourier expansion of the physical quantity $n(r) ; r$ is the position vector equal to $x \quad y \quad z^{T}$. The inverted lattice is clearly the lattice of the true regular lattice vector space in its Fourier space. The wave vector $k$ is then used to scan the irreducible Brillouin zone of the cell, and the Bloch periodicity is added to the cell boundary for calculation. A schematic of the cell and irreducible Brillouin zone is displayed in Figure 1.

(a)

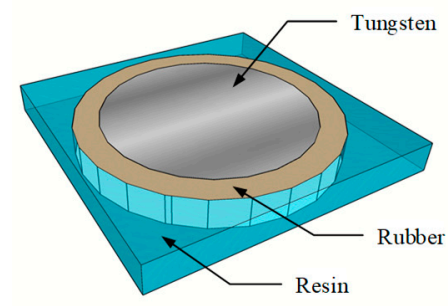

(b)

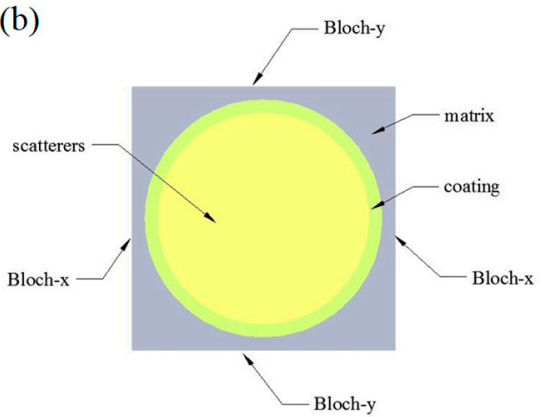

(c)

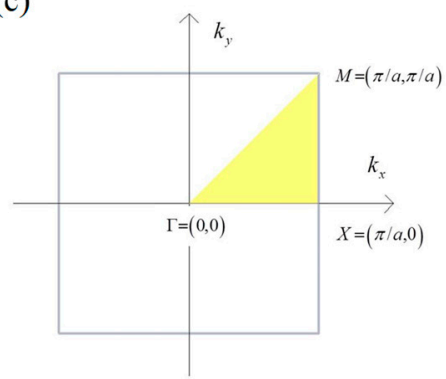

Figure 1. Cells and irreducible Brillouin zone: (a) is the 3D model of the single-layer phononic crystal plate cell and (b) is the top view of the cell. The yellow triangle in (c) is the irreducible Brillouin zone.

When a longitudinal acoustic wave is injected into the elastic body, it is transformed into an elastic wave that has both longitudinal and transverse components. For isotropic materials, the elastic wave equation can be expressed using the displacement components in three directions as follows:

$$
\begin{gathered}
\left\{\begin{array}{c}
\rho \frac{\partial^{2} u_{x}}{\partial t^{2}}=(\lambda+\mu) \frac{\partial \theta_{t}}{\partial x}+\mu \nabla^{2} u_{x}+\rho f_{x} \\
\rho \frac{\partial^{2} u_{x}}{\partial t^{2}}=(\lambda+\mu) \frac{\partial \theta_{t}}{\partial y}+\mu \nabla^{2} u_{y}+\rho f_{y} \\
\rho \frac{\partial^{2} u_{y}}{\partial t^{2}}=(\lambda+\mu) \frac{\partial \theta_{t}}{\partial y}+\mu \nabla^{2} u_{z}+\rho f_{z}
\end{array}\right. \\
\lambda=\frac{E v}{(1-2 v)(1+v)} \\
\mu=\frac{E}{2(1+v)}
\end{gathered}
$$

where $u_{x}, u_{y}, u_{z}$ are the displacement components in the $x, y$, and $z$ directions, respectively; $\theta_{t}$ is the total line-strain $\left(\theta_{t}=\varepsilon_{x}+\varepsilon_{y}+\varepsilon_{z}\right) ; f_{x}, f_{y}, f_{z}$ are the external force components of the unit mass in the $x$, 
$y$, and $z$ directions (unit: $\mathrm{N} / \mathrm{kg}$ ); $\lambda$ and $\mu$ are the Lamé elastic constants, and the unit is Pa; $\rho$ is the density; $E$ is Young's modulus; $v$ is Poisson's ratio; and $\nabla^{2}$ is the Laplace operator:

$$
\nabla^{2}=\frac{\partial^{2}}{\partial x^{2}}+\frac{\partial^{2}}{\partial y^{2}}+\frac{\partial^{2}}{\partial z^{2}}
$$

Using the finite element software to mesh the cells, the characteristic equations in the primitive cells are:

$$
\left(\boldsymbol{K}-\omega^{2} \boldsymbol{M}\right) \boldsymbol{U}=0
$$

where $K$ is the stiffness matrix of the nodes in the primitive cell, $M$ is the mass matrix of the nodes in the primitive cell, $U$ is the displacement matrix of the nodes in the primitive cell, and $\omega$ is the characteristic frequency.

COMSOL Multiphysics 5.4 was employed to directly solve the eigenvalue equation subject to the complex boundary conditions. The wave vector is then used to sweep the edges of the irreducible Brillouin zone. We thereby obtain the eigenvalue problem representing the relationship between the wave frequency and wave vector, that is, the dispersion relationship, also known as the band structure.

\section{Material and Method of STL}

The phononic crystals cavity plates comprise two phononic crystals plates separated by a cavity. Three-dimensional three-component local resonance phononic crystals were selected as the phononic crystals plate. A schematic of the phononic crystals plates cell is displayed in Figure 2. The cell size (a) is $100 \mathrm{~mm}$, the thickness of plates (t_p) is $10 \mathrm{~mm}$, the thickness of cavity $(\mathrm{H})$ is $10 \mathrm{~mm}$; epoxy resin is used as the matrix, and tungsten with a radius ( $\mathrm{r}$ ) of $46 \mathrm{~mm}$ is used as the scatterer. A silicone rubber layer with a thickness of $2 \mathrm{~mm}$ is placed between the matrix and the scatterer. The material density, Young modulus, and Poisson's ratio in the models are given in Table 1.

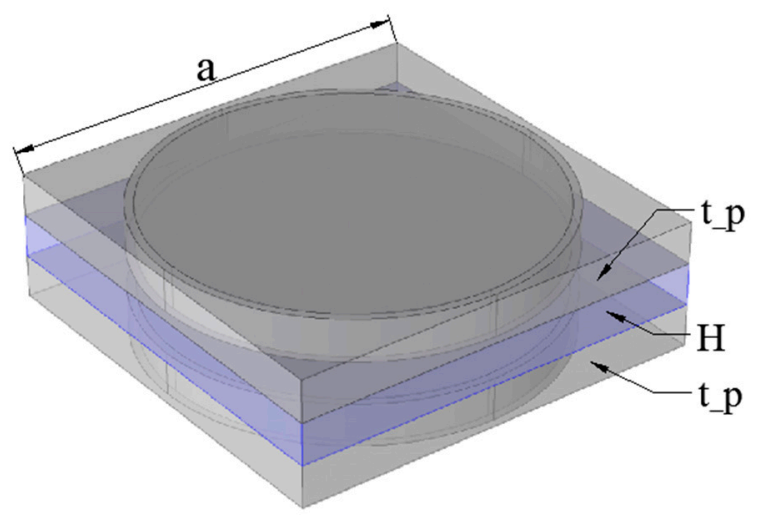

Figure 2. Phononic crystals cavity plates cell.

Table 1. Material parameters.

\begin{tabular}{cccc}
\hline Material & $\boldsymbol{\rho}\left(\mathbf{k g} / \mathbf{m}^{\mathbf{3}}\right)$ & $\mathbf{E}(\mathbf{P a})$ & $\boldsymbol{v}$ \\
\hline Resin & 1180 & $4.35 \times 10^{9}$ & 0.3679 \\
Rubber & 1300 & $1.175 \times 10^{5}$ & 0.46875 \\
Tungsten & 19350 & $3.54 \times 1011$ & 0.35 \\
\hline
\end{tabular}

STL simulation calculations for the phononic crystals plate and phononic crystals cavity plates are performed according to the structure of a standing wave tube. However, the standing wave tube method is only suitable for measuring soft materials such as porous materials. Because the acoustic properties of hard materials are greatly affected by the boundary conditions, when the standing wave tube tests fixed-supported hard materials, the sound insulation will produce false high values in the 
low-frequency domain [39]. Therefore, this article is based on the principle of the standing wave tube method, and continuity Floquet-Bloch periodic boundary conditions are added in the $\mathrm{x}$ and $\mathrm{y}$ directions to reflect the periodicity of the phononic crystals. The schematic diagram of the cycle model is shown in Figure 3, and one of the cycles is taken as the functional area explanation. The upper boundary (blue surface) of the emission zone is defined as the boundary condition of plane wave radiation, and an incident wave with a value of $1 \mathrm{~Pa}$ is defined. The lowermost region is the perfectly matched layers (PML). The incident wave is first transmitted to the upper plate of the phononic crystals cavity plates, then the acoustic radiation through the plate is transmitted to the cavity between plates, and then transmitted to the lower plate of the phononic crystals cavity plates, and finally dissipated by the PML layer. The STL formula is defined as

$$
\mathrm{STL}=20 \log _{10}\left(\frac{P 1}{P 2}\right)
$$

$P 1$ is the incentive pressure, which is $1 \mathrm{~Pa}$ in this model, and $P 2$ is the pressure in the integral $P 2$ area.
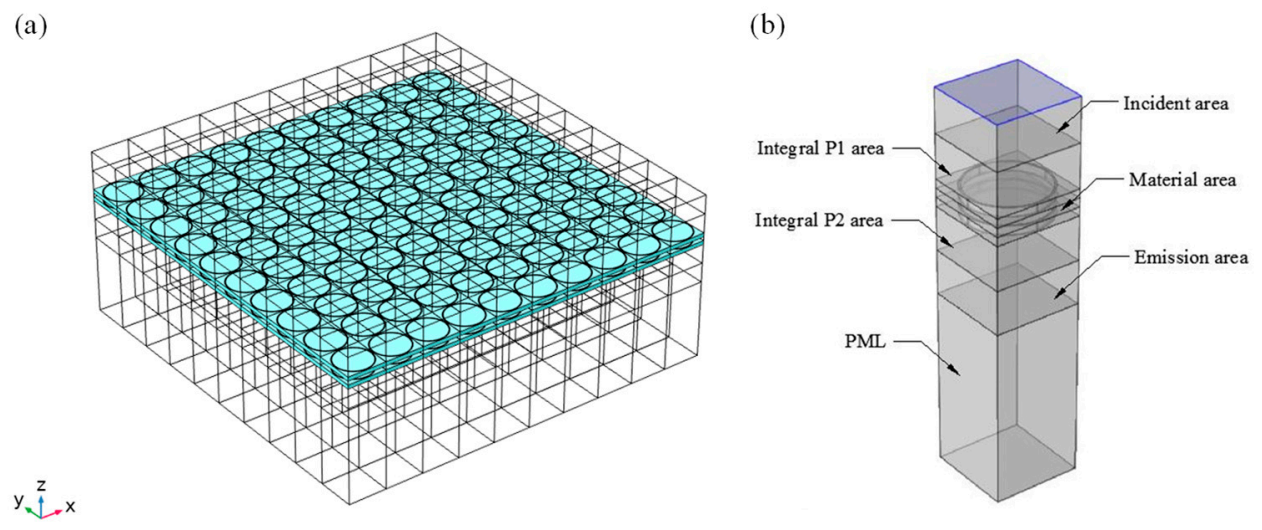

Figure 3. Sound transmission loss (STL) simulation model: (a) is the STL model of the finite structure and $(\mathbf{b})$ is the partition description of the STL model.

When the phononic crystals cavity plates are simulated, the acoustic physical field and solid mechanical physics field should be coupled and simulated. The coupling method involves the addition of multiphysics coupling equations at the acoustic-solid boundary. The following three sets of acoustic vibration characteristic equations, which are the cavity sound pressure wave equations, are used for the coupling calculations:

$$
\nabla^{2} P=\frac{1}{c^{2}} \frac{\partial^{2} P}{\partial t^{2}}
$$

where $P$ is the sound pressure, $c$ is the speed of sound, and $t$ is time;

$$
\frac{\partial P}{\partial n}=-\rho_{0} \ddot{w}
$$

where $\boldsymbol{n}$ is the direction normal to the plate surface, $\rho_{0}$ is the air density, and $w$ is the surface vibration displacement of the plate structure;

$$
\mathbf{D} \nabla^{4} w+\rho_{s} t_{p} \frac{\partial^{2}}{\partial t^{2}}=F_{m}-F_{p}
$$

where $\mathbf{D}$ is the bending stiffness of the plate, $\nabla^{4}$ is the reharmonic operator, $\rho_{s}$ is the plate density, $t_{p}$ is the plate thickness, $F_{m}$ is the source excitation, and $F_{p}$ is the acoustic excitation in the cavity. 


\section{Results and Discussion}

\subsection{Band Structure Analysis}

To fully capture the effect of the cavity structure on the STL of the phononic crystals plate, for a constant total thickness of the phononic crystals cavity plates, this study compares the STL obtained for three types of phononic crystals plate: (i) thickness equal to that of a single layer of the phononic crystals cavity plates, (ii) thickness equal to that of a double layer of the phononic crystals cavity plates, and (iii) equal to the total thickness of the phononic crystals cavity plates. In this paper, the structure of the main phononic crystals cavity plates is a $10 \mathrm{~mm}$ phononic crystals plate $+10 \mathrm{~mm}$ air layer $+10 \mathrm{~mm}$ phononic crystals plate. Therefore, the band structures of phononic crystals plate with thicknesses 10, 20, and $30 \mathrm{~mm}$ are calculated first. The results are presented in Figure 4 and Table 2. Through analysis, the band structure found to determine the main band gap is the sixth- and seventh-order bands. To make the comparison more intuitive, comparison of the bands is attempted. The sixth- to seventh-order bands of phononic crystals plate with different thicknesses are analyzed. The comparison analysis results are shown in Figure 4d. Figure 5 displays the modal for analysis of the band gap mechanism and the cause of the band gap difference.

(a)

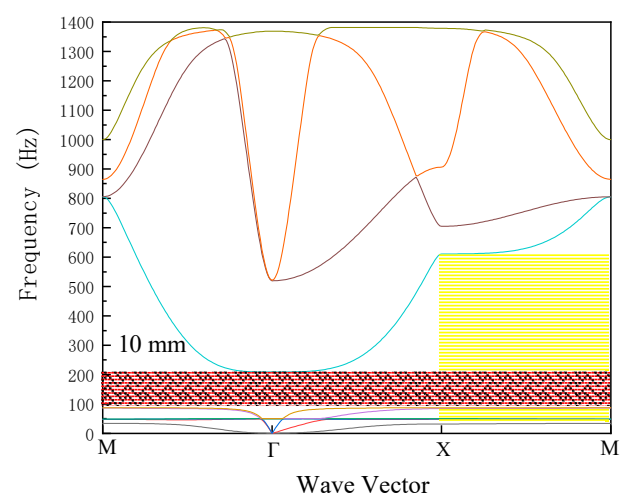

(c)

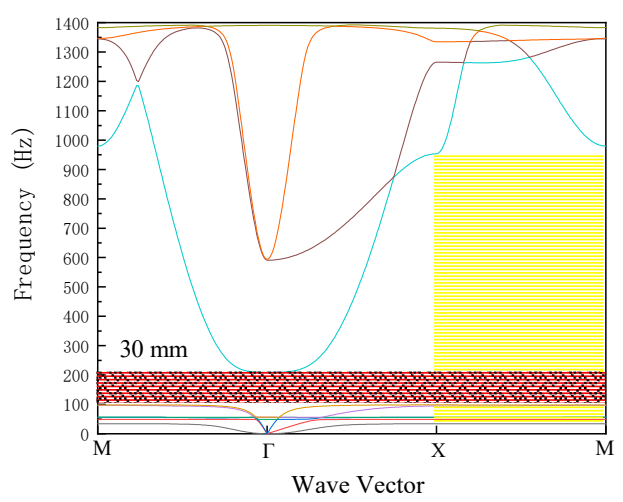

(b)

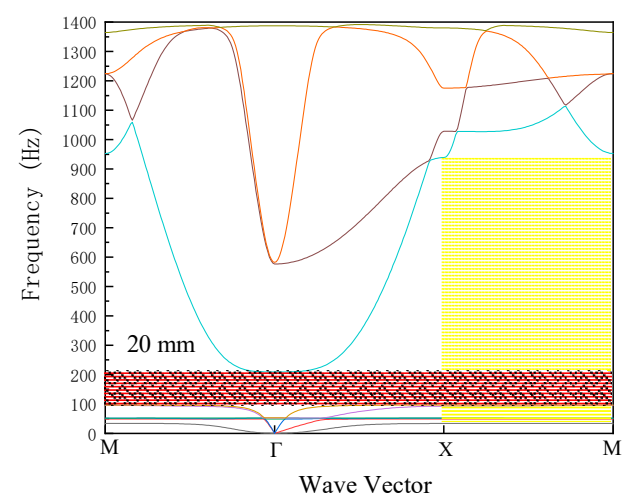

(d)

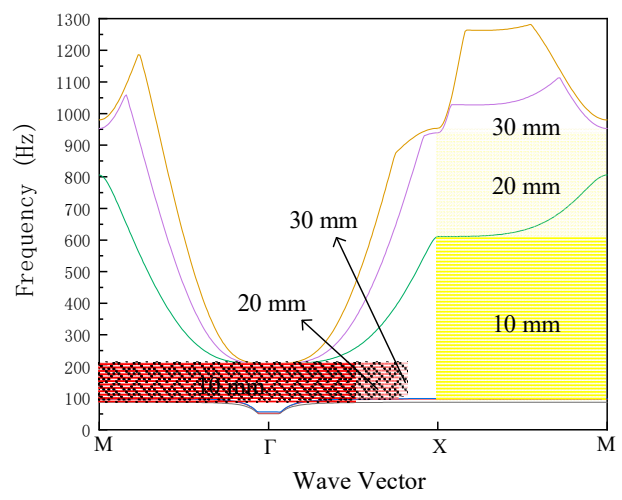

Figure 4. Band structure. The red area in the figure is the complete band gap, and the yellow area is the band gap in the X-M direction. Among them, the yellow and blue lines in $(\mathbf{a}-\mathbf{c})$ correspond to the sixth-order band and seventh-order band, respectively. The two-order bands are extracted and placed in (d) for comparison. (a) Band structure of $10 \mathrm{~mm}$-thick phononic crystals plate. (b) Band structure of $20 \mathrm{~mm}$-thick phononic crystals plate. (c) Band structure of $30 \mathrm{~mm}$-thick phononic crystals plate. (d) Comparison analysis band diagram (sixth- to seventh-order band structure of phononic crystals plate with various thicknesses). 
Table 2. Band gaps for 10, 20, and 30 mm-thick phononic crystals plate.

\begin{tabular}{ccccc}
\hline Band Position & $\begin{array}{c}\mathbf{1 0} \mathbf{~ m m ~ S t a r t ~ a n d} \\
\text { Stop Frequency } \\
\mathbf{( H z )}\end{array}$ & $\begin{array}{c}\mathbf{2 0} \mathbf{~ m m ~ S t a r t ~ a n d} \\
\text { Stop Frequency } \\
\mathbf{( H z )}\end{array}$ & $\begin{array}{c}\mathbf{3 0} \mathbf{~ m m ~ S t a r t ~ a n d ~} \\
\text { Stop Frequency } \\
\mathbf{( H z )}\end{array}$ & $\begin{array}{c}\text { Band Gap } \\
\text { Direction }\end{array}$ \\
\hline $1-2$ & $33.98-47.69$ & $34.04-48.76$ & $34.05-48.77$ & XM \\
$2-3$ & - & - & $49.15-56.1$ & XM \\
$4-5$ & $50-84.09$ & $52.26-92.51$ & $56.16-94.45$ & XM \\
$6-7$ & $87.04-208.59$ & $96.78-208.88$ & $98.57-208.93$ & complete \\
$6-7$ & $208.59-610.87$ & $208.88-939.03$ & $208.93-953.38$ & XM \\
\hline
\end{tabular}

(a)

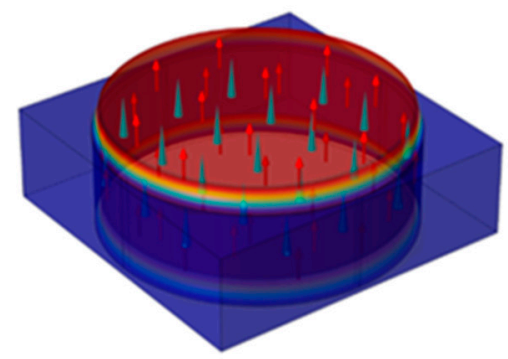

(c)

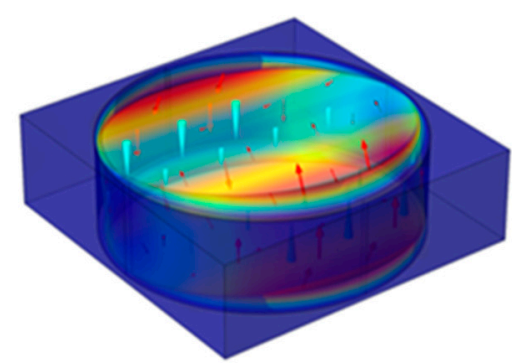

(e)

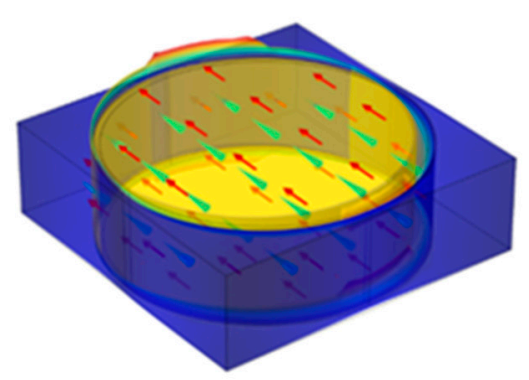

(g)

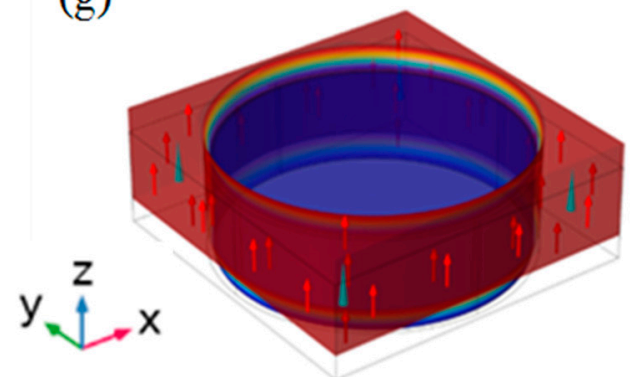

(b)

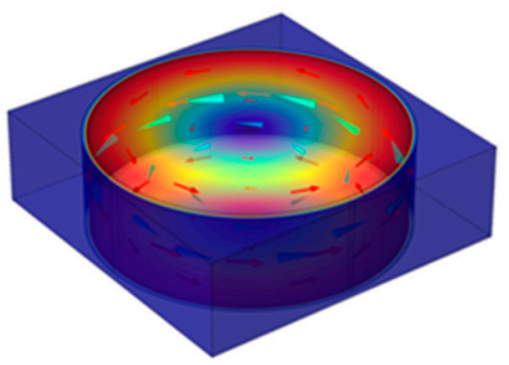

(d)

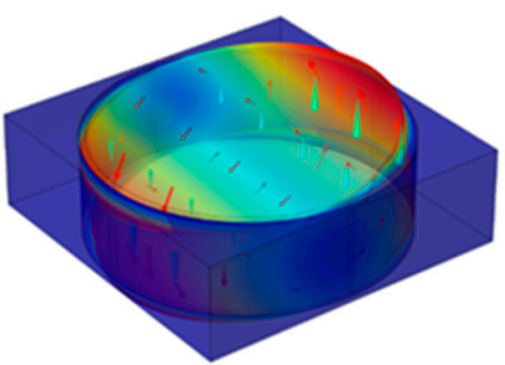

(f)

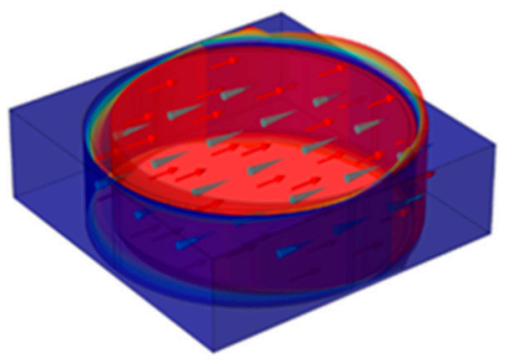

(h)

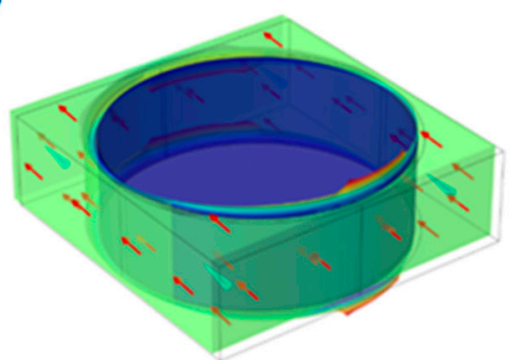

Figure 5. Modal diagram: (a) first band, (b) second band (c) third band (d) fourth band, (e) fifth band, (f) sixth band, (g) lower edge of seventh band, (h) lower edge of seventh band in the X-M direction. 
According to Figures 4 and 5 and Table 2, changing the thickness exerts little effect on the upper edge of the complete band gap of the phononic crystals plate, and the lower edge is stable in the range $208.59-208.93 \mathrm{~Hz}$. However, a certain effect is exerted on the lower edge. From $87.04 \mathrm{~Hz}$ at $10 \mathrm{~mm}$ to $96.78 \mathrm{~Hz}$ at $20 \mathrm{~mm}$, and $98.57 \mathrm{~Hz}$ at $30 \mathrm{~mm}$, nonlinear growth with a decreasing slope occurs, fluctuating by approximately $10 \mathrm{~Hz}$. In terms of the directional band gap, the first band gap of the $\mathrm{X}-\mathrm{M}$ direction is not significantly different in various plate thicknesses. The modes are the vibration of the scatterer along the $\mathrm{z}$-axis and the rotation of the scatterer about the z-axis. This is explained by noting that the physical quantity that determines the first band gap of the $\mathrm{X}-\mathrm{M}$ direction is mainly the volume physical quantity. The second band gap change is more obvious in the $\mathrm{X}-\mathrm{M}$ direction at the $2-3$ band position. The difference obtained between 10 and $20 \mathrm{~mm}$ is too small at this band position, only approximately $1 \mathrm{~Hz}$, so a band gap is not formed, whereas the $30 \mathrm{~mm}$-thick plate has a band gap with a width close to $7 \mathrm{~Hz}$. The calculation of the modalities is such that the scatterer rotates around the $z$-axis and vibrates along the $x$-axis, indicating that the physical quantities determining the second band gap in the X-M direction are mainly surface physical quantities. The third band gap in the X-M direction is at the $4-5$ band position. The modes are such that the scatterer both rotates around and vibrates along the y-axis. The band gap width is mostly stable at approximately $35-40 \mathrm{~Hz}$. The band gap change is similar to the band gap in the first direction. The largest change is the fourth band gap in the complete direction at the 6-7 band position, and the modes are the scatterer vibrating along the $x$-axis and the matrix vibrating along the $z$-axis. The lower edge of the band gap is the same, but the upper edge of the band gap changes from $610.87 \mathrm{~Hz}$ at $10 \mathrm{~mm}$ to $939.03 \mathrm{~Hz}$ at $20 \mathrm{~mm}$ to $953.38 \mathrm{~Hz}$ at $30 \mathrm{~mm}$. A nonlinear growth characteristic is exhibited with a decreasing slope that is consistent with the lower edge of the full band gap, which changes by approximately $343 \mathrm{~Hz}$. Because the band that determines the main band gap is the sixth- to seventh-order band, the band diagrams of the sixth to seventh bands of the phononic crystals plate for various thicknesses are compared and analyzed, so the color of the band gap from 10 to $30 \mathrm{~mm}$ changes gradually. To facilitate observation, the full band gap is scaled to various degrees in the horizontal direction according to proportions in the vertical direction. Following this operation, the various differences and changes in the previous analysis can be observed intuitively in Figure 4d.

\subsection{Influence of Phononic Crystals Plate Structure on the STL of the Plate and the Phononic Crystals Cavity Plates}

Based on the band structure and modal analysis, the STL of the phononic crystals plate under various conditions is calculated. First, the STLs of phononic crystals plate and phononic crystals cavity plates with various thicknesses were calculated. Comparison analysis of the phononic crystals plate and phononic crystals cavity plates is then performed, and the effect of scatterer radius $r$ on phononic crystals plate and phononic crystals cavity plates of various thicknesses is determined.

Figure 6 illustrates that increasing the thickness of the phononic crystals plate from 10 to 20 or $30 \mathrm{~mm}$ results in an increase in the average STL by approximately $5 \mathrm{~dB}$; the peak STL increases from 63 to 66 to $69 \mathrm{~dB}$, respectively-by $3 \mathrm{~dB}$ for each $10 \mathrm{~mm}$ in thickness. However, the average STL for the phononic crystals cavity plates with $\mathrm{h}=10+10+10 \mathrm{~mm}$ is considerably higher, with its peak value being $100 \mathrm{~dB}$, more than $30 \mathrm{~dB}$ greater than that of the phononic crystals plate with different thicknesses. The homogeneous cavity plates case was calculated as a comparison, and the result showed that although its STL has a certain increase at $140 \mathrm{~Hz}$, it is only $25 \mathrm{~dB}$, which is much smaller than the phononic crystal cavity plates. Notably, the STL curve has an inverted U shape for the phononic crystals cavity plates at frequencies lower than $60 \mathrm{~Hz}$ and higher than $200 \mathrm{~Hz}$, and this is not observed for the phononic crystals plate. Calculating the mode of the phononic crystals demonstrates that the scatterer vibrates along the z-axis and the matrix vibrates along the z-axis within these two ranges. Therefore, the inverted U shapes are STL-inverted U-shaped attenuation caused by resonance resulting from the coupling of the phononic crystals plate and air acoustic vibration. Because the shape of the curve resembles a cave, it may be referred to as a "cavity cave". 


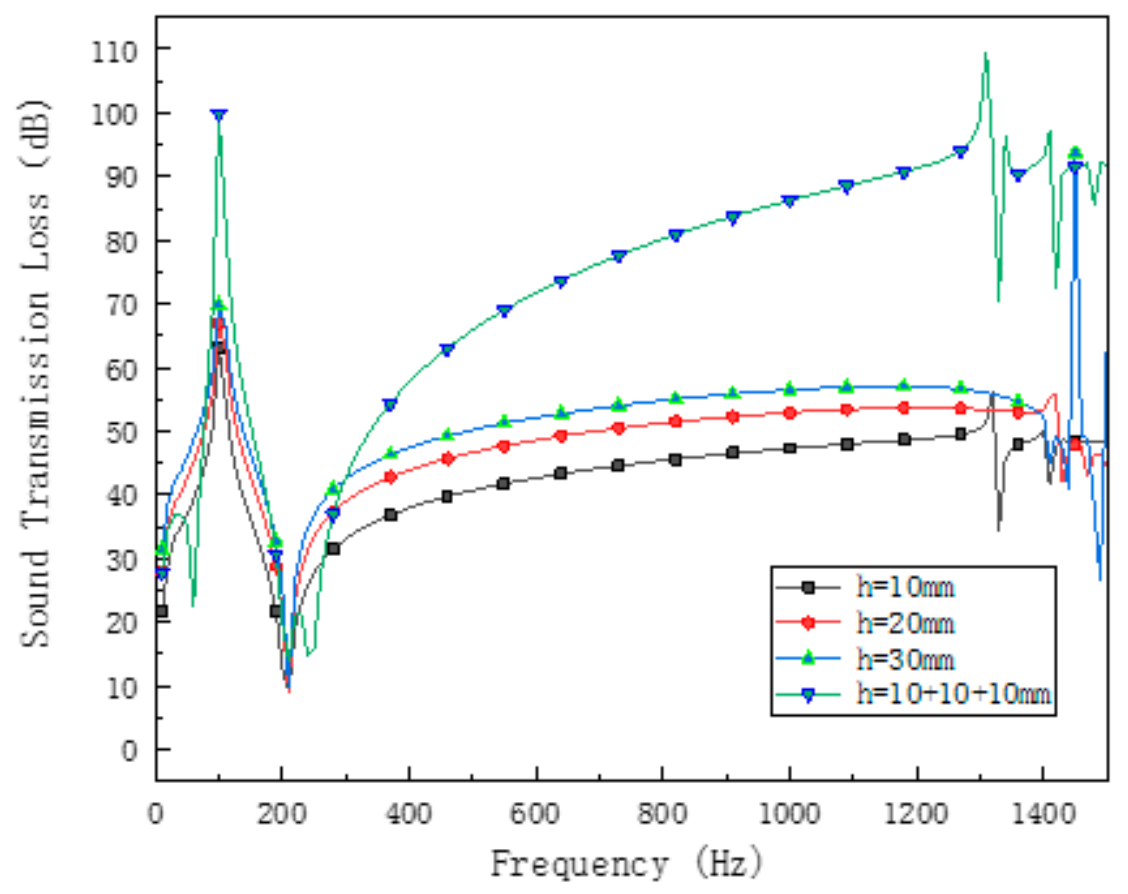

Figure 6. STL of phononic crystals cavity plates $(\mathrm{h}=10 \mathrm{~mm}+10 \mathrm{~mm}+10 \mathrm{~mm})$, homogeneous cavity plates, and phononic crystals plate with various thicknesses: $h=10 \mathrm{~mm}, \mathrm{~h}=20 \mathrm{~mm}$ (the same mass with phononic crystals cavity plates), and $\mathrm{h}=30 \mathrm{~mm}$ (the same volume with phononic crystals cavity plates). The peak and bottom values of all types of STL are the same, 100 and $210 \mathrm{~Hz}$, respectively. This is highly consistent with the calculation result of the energy band, which proves the correctness of both.

These characteristics are unaffected when the scatterer $r$ is changed. As indicated in Figure 7, the peak and average STLs of the phononic crystals cavity plates considerably exceed those of the single plate structure of thickness $10 \mathrm{~mm}$ and the phononic crystals plate with the same total mass ( $20 \mathrm{~mm}$ thickness) and total volume (30 mm thickness) as the cavity plate. As the scatterer radius $\mathrm{r}$ is decreased from $46 \mathrm{~mm}$ in $2 \mathrm{~mm}$ increments to $36 \mathrm{~mm}$, the frequencies corresponding to the first few peaks decrease accordingly for both the phononic crystals plate and phononic crystals cavity plate. The difference between the two plates is that the size of the peak of the phononic crystals plate increases first and then decreases, whereas the peak for the phononic crystals cavity plates gradually decreases. The reason for consideration is that when the phononic crystals plate is too thin, the kinetic energy of the scatterer cannot be fully excited. The phononic crystals cavity plate can more easily excite the kinetic energy of the scatterer due to the existence of the cavity. At the same time, the STL peaks and dips denser as the radius of the scatterer decreases, owing to the band gap decreases. The area near the first peak corresponds to the first complete band gap of the phononic crystals, so the STL in this band gap range is more worthy of study. 
(a)

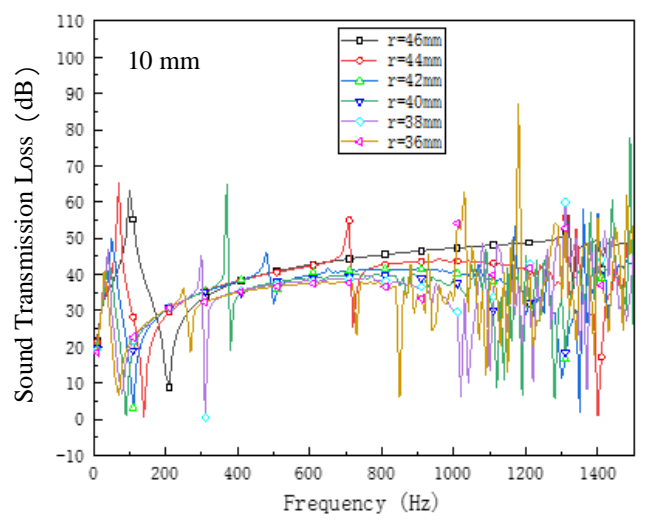

(c)

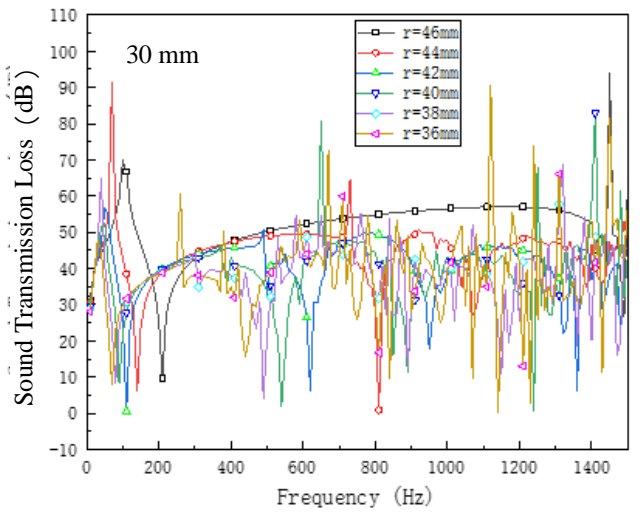

(b)

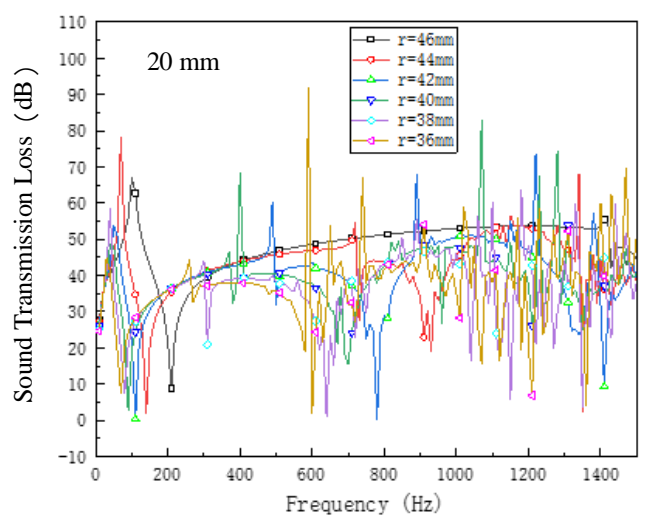

(d)

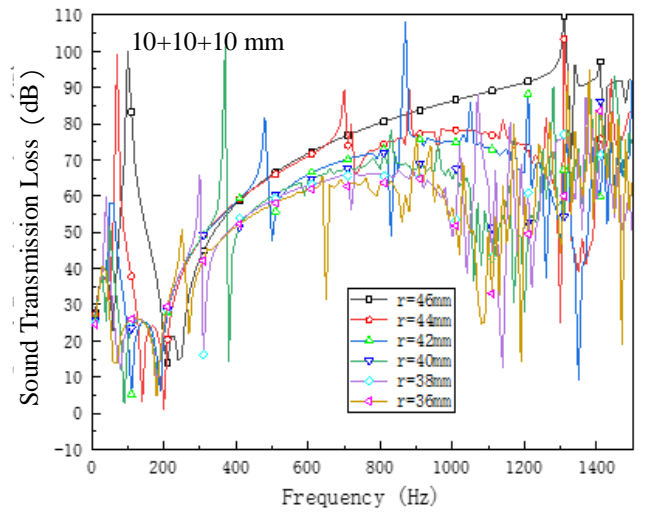

Figure 7. Effect of $r$ on the STL: (a) effect of $r$ on the STL for a $10 \mathrm{~mm}$-thick phononic crystals plate, (b) effect of $\mathrm{r}$ on the STL for a $20 \mathrm{~mm}$-thick phononic crystals plate, (c) effect of $\mathrm{r}$ on the STL for a $30 \mathrm{~mm}$-thick phononic crystals plate, and (d) effect of $\mathrm{r}$ on the STL of the phononic crystals cavity plates.

First, according to presented results, when $\mathrm{r}$ is $46 \mathrm{~mm}$, the band gap of a $10 \mathrm{~mm}$-thick phononic crystals plate is $87.04-208.59 \mathrm{~Hz}$. An STL greater than $20 \mathrm{~dB}$ is defined as effective noise reduction. The possibility of distortion of the standing wave tube when testing low frequencies should be considered. The peak is taken as the effective noise reduction starting point. To illustrate the problem more clearly, the STL is localized in the 10-200 Hz range and plotted in Figure 8. As $\mathrm{r}$ is changed from 46 to $36 \mathrm{~mm}$ in increments of $2 \mathrm{~mm}$ for the $10 \mathrm{~mm}$-thick phononic crystals plate, the effective noise reduction range is 100-190, 70-120, 50-90, 40-70, 40-60, and 30-50 Hz, with respective range widths of $90,50,40,30,20$, and $20 \mathrm{~Hz}$, showing a nonlinear decrease with a decreasing slope; the extreme value is $65 \mathrm{~dB}$ at $70 \mathrm{~Hz}$. For $\mathrm{r}$ changed from 46 to $36 \mathrm{~mm}$ for the $20 \mathrm{~mm}$-thick phononic crystals plate, the effective noise reduction range is 100-200, 70-130, 50-100, 40-80, 30-60, and 30-50 Hz; these ranges have respective widths of 100,60,50,40,30, and $20 \mathrm{~Hz}$. As for the $10 \mathrm{~mm}$-thick plate, the range exhibits a nonlinear decrease with a gradually decreasing slope. The difference with the $100 \mathrm{~mm}$-thick plate is that the lower edge of the effective noise reduction section is approximately $10 \mathrm{~Hz}$ higher, and the width is approximately $10 \mathrm{~Hz}$ greater. The extreme value is $78 \mathrm{~dB}$ at $70 \mathrm{~Hz}$, which is an increase of $13 \mathrm{~dB}$ compared with that of the $10 \mathrm{~mm}$-thick plate. For the $30 \mathrm{~mm}$-thick phononic crystals plate, the effective noise reduction range as $\mathrm{r}$ is changed from 46 to $36 \mathrm{~mm}$ in increments of $2 \mathrm{~mm}$ is $100-200$, 70-130, 50-100, 50-80, 40-70, and 30-60 Hz, with respective range widths of 100, 60, 50, 40, 30, and $30 \mathrm{~Hz}$. As for the other two plates, the range exhibits a nonlinear decrease with a decreasing slope. The difference with the $20 \mathrm{~mm}$-thick plate is that when $\mathrm{r}$ is less than or equal to $40 \mathrm{~mm}$, the upper and lower edges of the effective noise reduction section are enlarged to a certain extent; the width is increased by an average of approximately $5 \mathrm{~Hz}$. The extreme value is $91 \mathrm{~dB}$ at $70 \mathrm{~Hz}$, which is $13 \mathrm{~dB}$ 
higher than for the $20 \mathrm{~mm}$-thick plate, thus showing a clear linear correlation with the changes of $20 \mathrm{~mm}$ and $10 \mathrm{~mm}$.

(a)

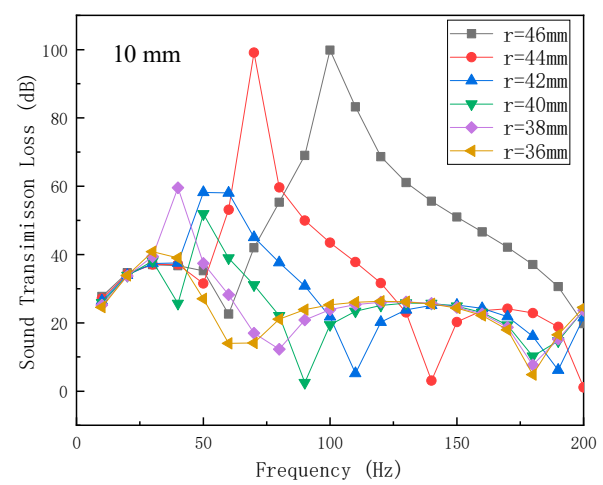

(c)

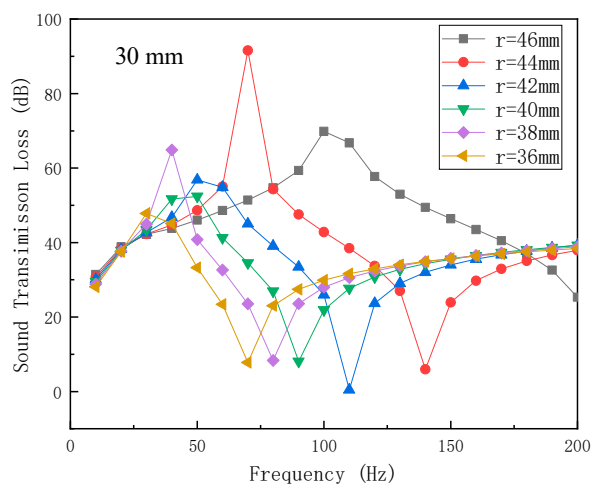

(b)

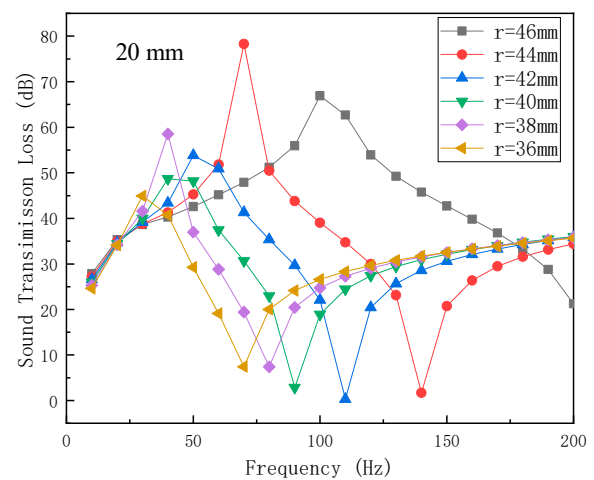

(d)

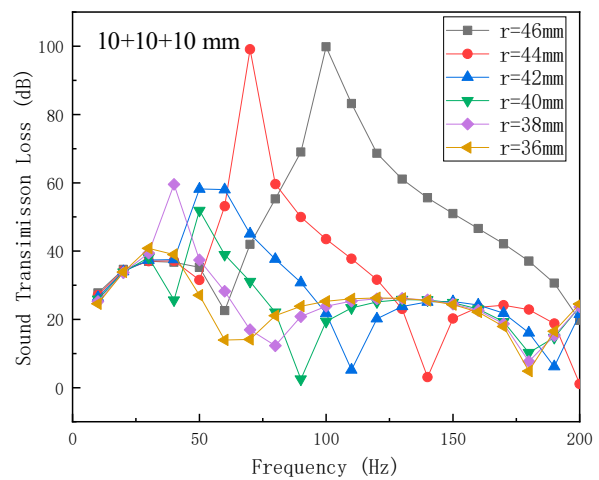

Figure 8. Effect of $\mathrm{r}$ on the local STL: (a) local STL of a $10 \mathrm{~mm}$-thick phononic crystals plate, (b) local STL of a $20 \mathrm{~mm}$-thick phononic crystals plate, (c) local STL of a $30 \mathrm{~mm}$-thick phononic crystals plate, and (d) local STL of the phononic crystals cavity plates.

As $\mathrm{r}$ is altered from 46 to $36 \mathrm{~mm}$ in increments of $2 \mathrm{~mm}$, the effective noise reduction range of the phononic crystals cavity plates is 100-200, 70-130, 50-100, 50-80, 40-60, and 30-50 Hz, with respective range widths of $100,60,50,30,20$, and $20 \mathrm{~Hz}$; as for the phononic crystals plate, the ranges exhibit a nonlinear decrease with decreasing slope. The effective noise reduction width and position are maintained near the average of the three-thickness phononic crystals plate. The difference is that at the extreme value, the transmission loss is $100 \mathrm{~dB}$ at $100 \mathrm{~Hz}$, whereas at the second extreme, the transmission loss is still high at $99 \mathrm{~dB}$ at $70 \mathrm{~Hz}$. The overall trend is such that the STL for the phononic crystals cavity plates is significantly better than that of the ordinary phononic crystals plate. Through analysis of the aforementioned data, the noise reduction performance of the phononic crystals cavity plates introduced into the cavity structure has a qualitative improvement. When the board structure is consistent, compared with that for the $10 \mathrm{~mm}$-thick phononic crystals plate, the average effective noise reduction frequency range is improved by approximately $15 \mathrm{~Hz}$, and the extreme value is improved by $35 \mathrm{~dB}$. When the total mass is the same as that of a $20 \mathrm{~mm}$-thick phononic crystals plate, the average effective noise reduction frequency domain is improved by approximately $5 \mathrm{~Hz}$, and the extreme value is improved by $22 \mathrm{~dB}$. When the total volume is the same as that of the $30 \mathrm{~mm}$-thick phononic crystals plate, although the average effective noise reduction frequency domain is not considerably different, the extreme value is increased by $9 \mathrm{~dB}$ and the quality is reduced by one-third. Overall comparison reveals that in the frequency range $0-1500 \mathrm{~Hz}$, the average STL of the phononic crystals cavity plates is much larger than that of the phononic crystals plate with various thicknesses, providing a clear advantage. 


\subsection{Effect of Cavity Thickness on STL of Phononic Crystals Cavity Plates}

The aforementioned research clarifies the effect of cavity thickness and plate thickness on the STL of the phononic crystals cavity plates. Various cavity thicknesses are used: 1, 2, 3, 5, 10, 15, and $20 \mathrm{~mm}$. (When the cavity thickness is larger, the plate-cavity coupling effect gradually disappears and the experimental results are like two separate plates. Since a too large cavity does not reflect better acoustic performance, and the increased floor space is not conducive to later experiments and engineering applications, the effect of thicker cavities was not analyzed). To clarify the STL comparison, the STL is taken at $10-200 \mathrm{~Hz}$ when the cavity thickness is 1, 10, or $20 \mathrm{~mm}$. To ensure the rigor of the research conclusions, after analyzing the effect of cavity thickness on the STL when the longitudinal influence of the phononic crystals plate thickness of $10 \mathrm{~mm}$ is analyzed, the STL values for phononic crystals plate of thickness 1 and $20 \mathrm{~mm}$ are calculated on the basis of the phononic crystals plate with $10 \mathrm{~mm}$ thickness. For the thickness of 1 and $20 \mathrm{~mm}$ lateral analysis, a phononic plate thickness of $10 \mathrm{~mm}$ is used.

As demonstrated by Figure 9, cavity thickness does not affect the location of STL peaks; only the STL values and deformation of the "cavity cave" change. As the cavity thickness is increased, the average STL gradually increases, and the extreme value increases nonlinearly with a decreasing slope, from $78 \mathrm{~dB}$ at a cavity thickness of $1 \mathrm{~mm}$ to $100 \mathrm{~dB}$ at a cavity thickness of $10 \mathrm{~mm}$, and then to $104 \mathrm{~dB}$ at $20 \mathrm{~mm}$ cavity thickness. The width of the "cavity cave" also gradually decreases, which means that the average STL increases. Therefore, the larger the cavity, the better the sound insulation effect of the phononic crystals cavity plates. Figures 10 and 11 indicate that the aforementioned rules are mostly constant whether the plate thickness is 10 or $20 \mathrm{~mm}$. As the cavity thickness is increased, the average STL increases. The difference is that when the thickness of the plate is $1 \mathrm{~mm}$, the extreme value and width of the first STL peak are unaffected by the thickness of the cavity. However, when the cavity thickness is $3 \mathrm{~mm}$, a large change occurs, and this change is beneficial, which can be further investigated in the future.

(a)

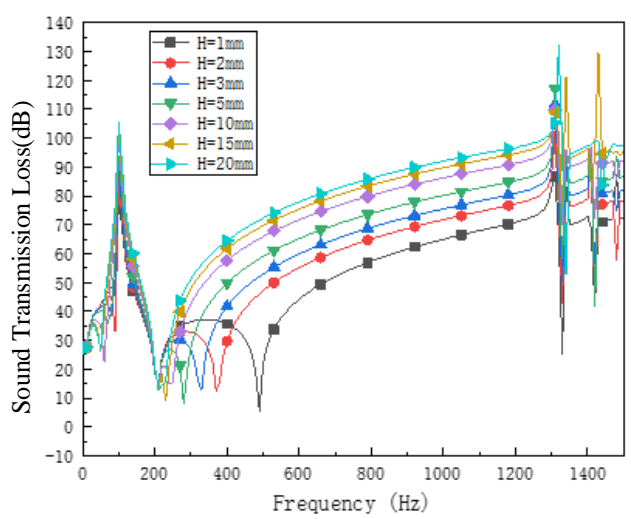

(b)

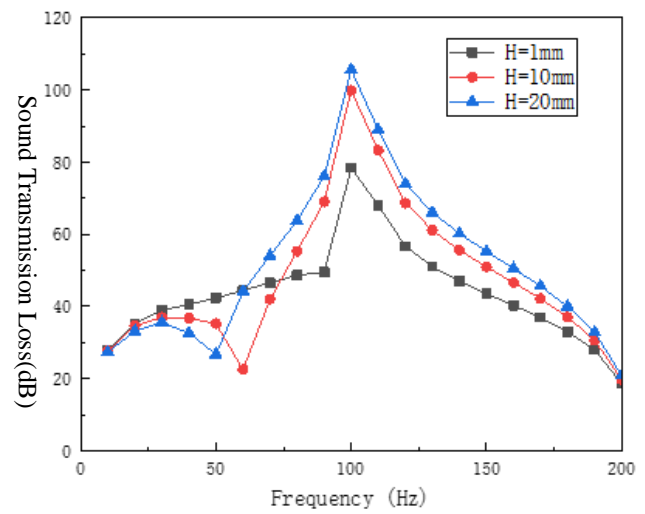

Figure 9. Effect of cavity thickness on STL for phononic crystals plate thickness of $10 \mathrm{~mm}$ : (a) 0-1500 Hz and (b) 0-200 Hz. 
(a)

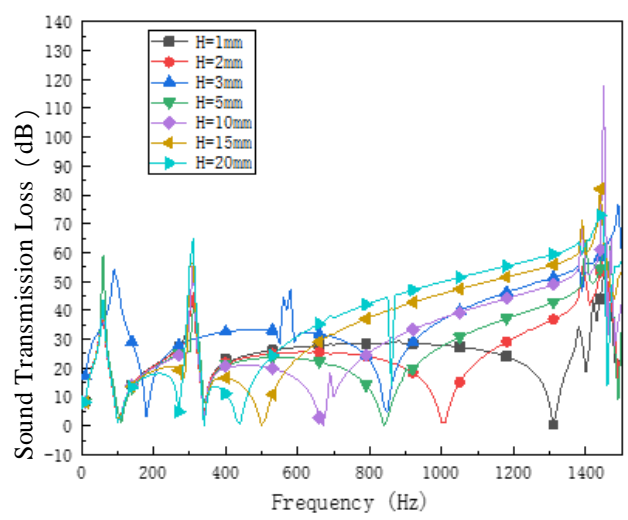

(b)

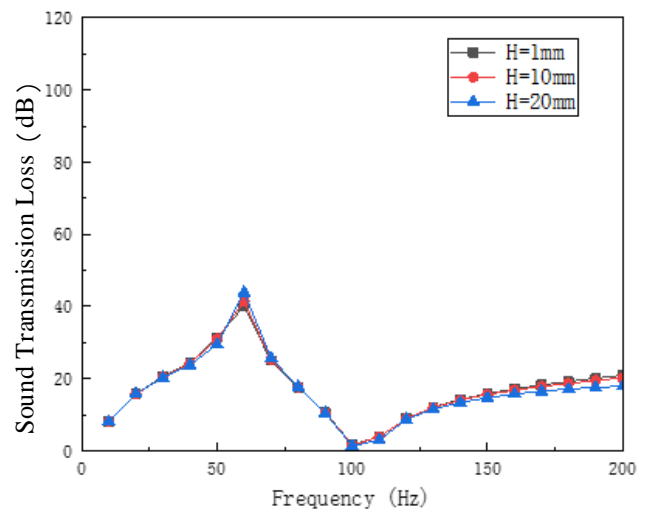

Figure 10. Effect of cavity thickness on STL for phononic crystals plate thickness of $1 \mathrm{~mm}$ : (a) $0-1500 \mathrm{~Hz}$ and (b) $0-200 \mathrm{~Hz}$.

(a)

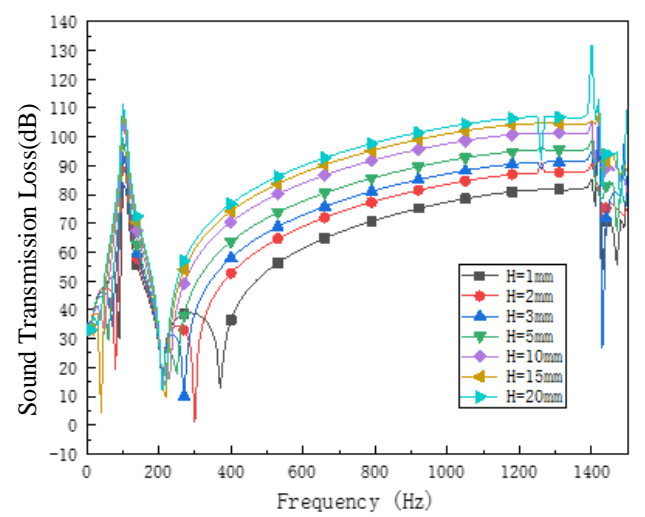

(b)

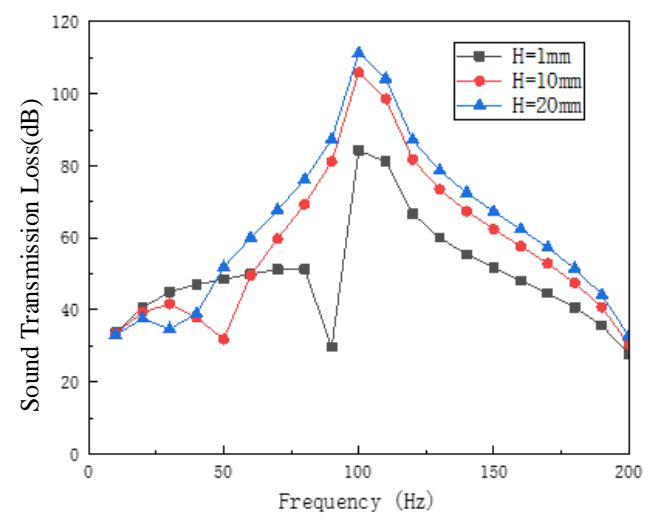

Figure 11. Effect of cavity thickness on STL for phononic crystals plate thickness of $20 \mathrm{~mm}$ : (a) 0-1500 Hz and (b) 0-200 Hz.

\subsection{Effect of Plate Thickness on STL of Phononic Crystals Cavity Plates}

The effects on the phononic crystals cavity plates' STL for plate thicknesses 1, 2, 3, 5, 10, 15, and $20 \mathrm{~mm}$ are examined. (The reason for the effect of the thicker plates was not analyzed but is similar to the thicker cavities.) According to other research, and combining the effect of plate thickness on the STL of the phononic crystals cavity plates, the STL is measured at $0-200 \mathrm{~Hz}$ for plate thicknesses of 1, 2, 3,5 , or $20 \mathrm{~mm}$, taking the complete "cavity cave" graphics for each plate thickness as a partial map. For a cavity thickness of $10 \mathrm{~mm}$ in the phononic crystals cavity plates, lateral comparison analysis is performed.

Figure 12 illustrate that plate thickness not only affects the location and size of STL peaks but also causes deformation of the "cavity cave." When the plate thickness is $1 \mathrm{~mm}$, the peak is $43 \mathrm{~dB}$ at $60 \mathrm{~Hz}$; when the plate thickness is $2 \mathrm{~mm}$, the peak is $62 \mathrm{~dB}$ at $80 \mathrm{~Hz}$; when the plate thickness is $3 \mathrm{~mm}$, the peak is $76 \mathrm{~dB}$ at $90 \mathrm{~Hz}$; when the plate thickness is $5 \mathrm{~mm}$, the peak is $98 \mathrm{~dB}$ at $100 \mathrm{~Hz}$; and when the plate thickness is $20 \mathrm{~mm}$, the peak value of $104 \mathrm{~dB}$ appears at $60 \mathrm{~Hz}$. This shows that as the thickness of the plate is increased, the average STL gradually increases, the position at which the STL peak appears gradually moves in the direction of higher frequencies, and the peak value increases nonlinearly as the slope decreases. 
(a)

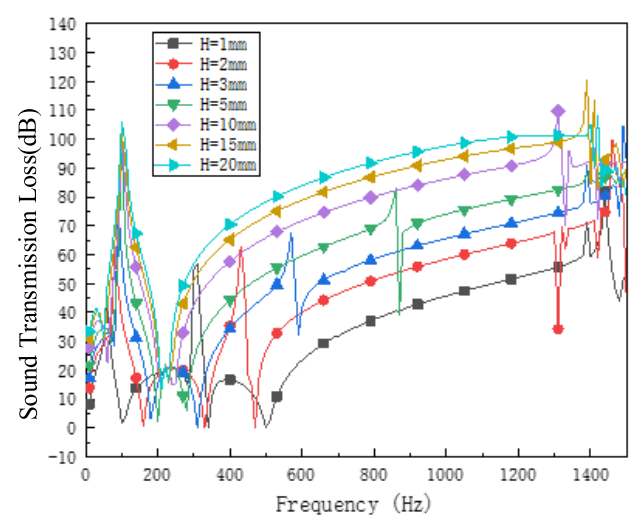

(b)

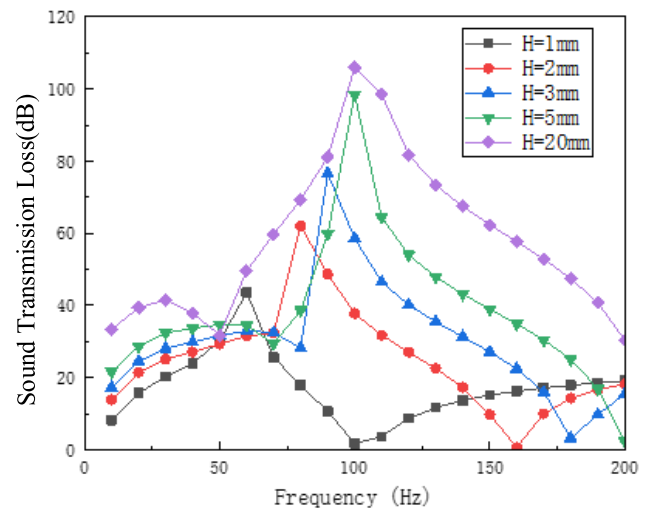

Figure 12. Effect of plate thickness on STL for a cavity thickness of $10 \mathrm{~mm}$ : (a) $0-1500 \mathrm{~Hz}$ and (b) 0-200 Hz.

According to Figure 13, when the thickness of the plate is $1 \mathrm{~mm}$, the "cavity cave" starts at $100 \mathrm{~Hz}$ and ends at $340 \mathrm{~Hz}$, and the hole width is $240 \mathrm{~Hz}$; when the plate thickness is $2 \mathrm{~mm}$, the "cavity cave" spans $160-330 \mathrm{~Hz}$, and the hole width is $170 \mathrm{~Hz}$; when the plate thickness is $3 \mathrm{~mm}$, the "cavity cave" spans $180-310 \mathrm{~Hz}$, and the hole width is $130 \mathrm{~Hz}$; when the plate thickness is $5 \mathrm{~mm}$, the "cavity cave" spans 200-280 Hz, and the hole width is $80 \mathrm{~Hz}$; when the plate thickness is $10 \mathrm{~mm}$, the "cavity cave" spans $210-240 \mathrm{~Hz}$, and the hole width is $30 \mathrm{~Hz}$; and when the plate thickness is 15 or $20 \mathrm{~mm}$, the "cavity cave" spans 210-230 Hz, and the hole width is $20 \mathrm{~Hz}$. The width of the "cavity cave" thus gradually decreases as the plate thickness is increased, such that the starting frequency increases and the end frequency decreases; the rate of decrease becomes lower and lower, causing the average STL to increase. Therefore, the thicker the plate, the better the sound insulation effect of the phononic crystals cavity plates.

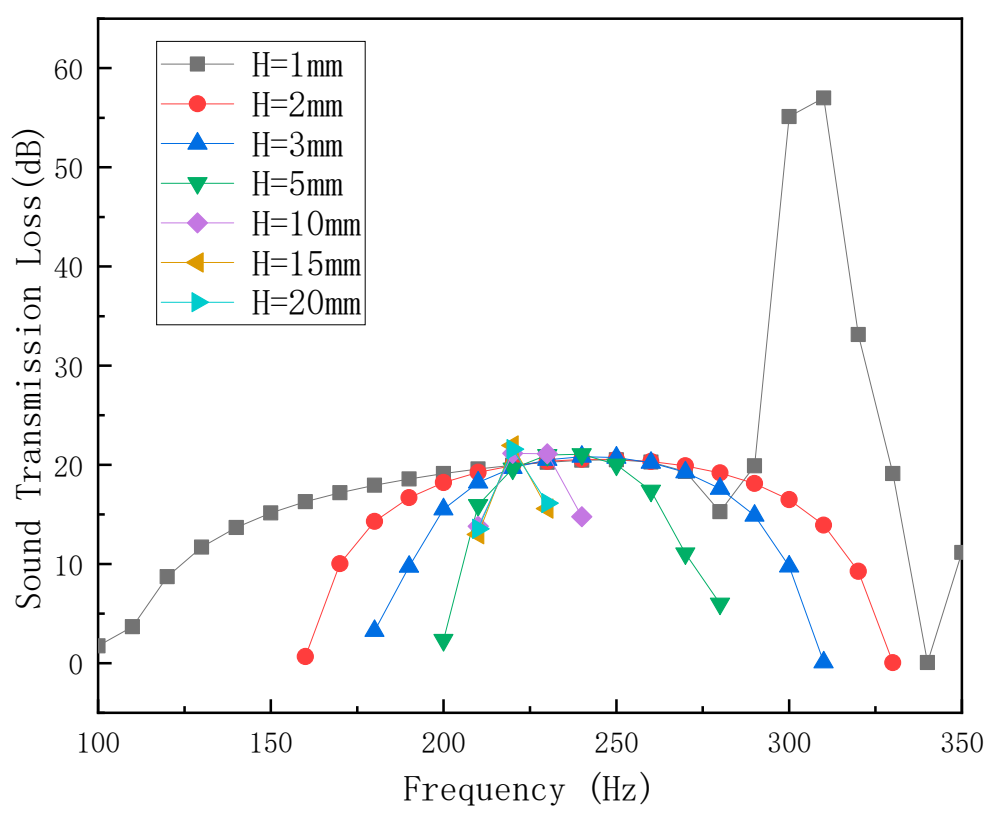

Figure 13. Effect of plate thickness on the cavity cave for cavity thickness of $10 \mathrm{~mm}$.

Figures 14 and 15 illustrate that the aforementioned rules are mostly the same when the plate thickness is 1 or $20 \mathrm{~mm}$. As the plate thickness is increased, the average STL gradually increases, the position of the STL peak gradually moves toward higher frequencies, and the peak gradually decreases by an increasing slope. Notably, the change in the "cavity cave" is greatest when the cavity thickness is 
$1 \mathrm{~mm}$; the change is centered when the cavity thickness is $10 \mathrm{~mm}$, and the change is minimal when the cavity thickness is $20 \mathrm{~mm}$. This shows that although the existence of the "cavity cave" is caused by the appearance of the cavity structure, it is a consequence of the acoustic-vibration coupling between the cavity and phononic crystals plate. Analyzing the vibration displacement diagram at the end of the "cavity cave" enables clear understanding of the mechanism. In Figure 16, the left image represents the first "cavity cave" and the right image represents the second "cavity cave." The mechanism is such that the phononic crystals plate is located at the beginning of the corresponding band gap because phononic crystals are located in the cavity. The scatterer or matrix of the upper and lower sides of the cavity in the opposite phase increases the sound transmission efficiency. Therefore, changes to the "cavity cave" are inseparably related to plate thickness and cavity thickness.

(a)

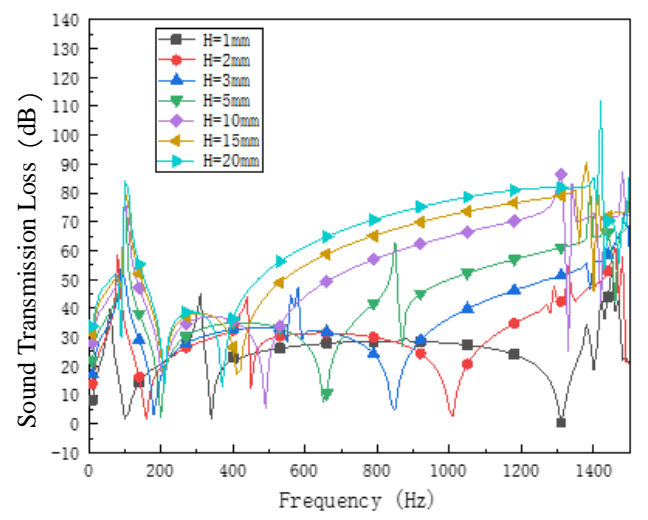

(b)

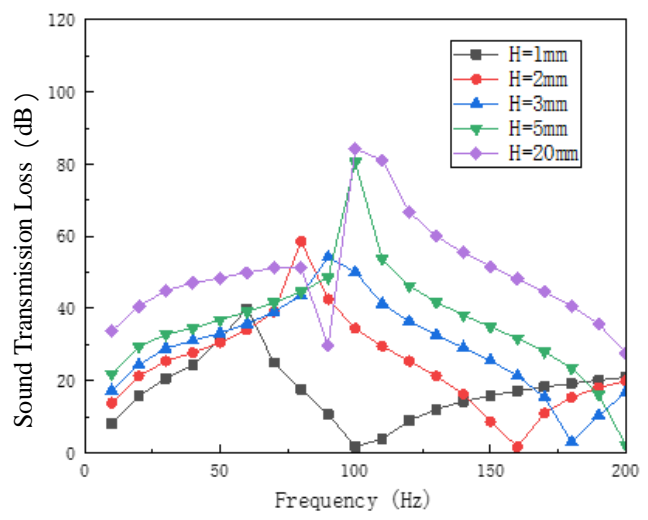

Figure 14. Effect of plate thickness on STL for cavity thickness of $1 \mathrm{~mm}$ : (a) 0-1500 Hz and (b) 0-200 Hz.

(a)

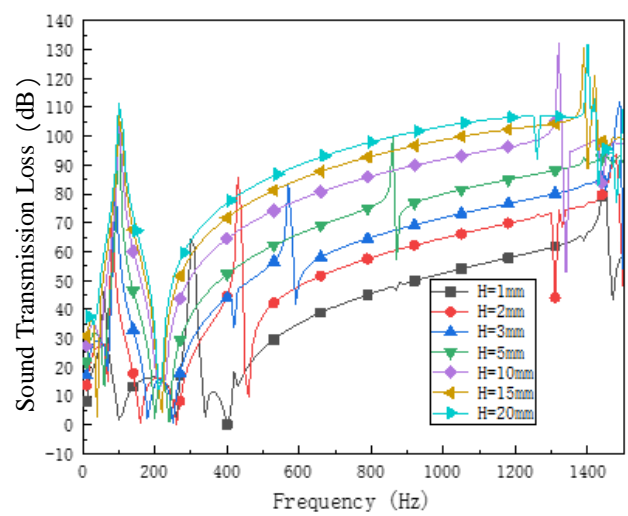

(b)

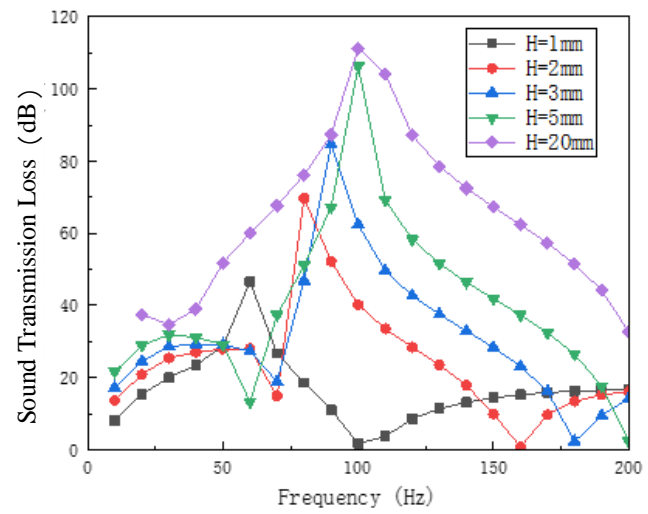

Figure 15. Effect of plate thickness on STL for cavity thickness of $20 \mathrm{~mm}$ : (a) 0-1500 Hz and (b) 0-200 Hz.
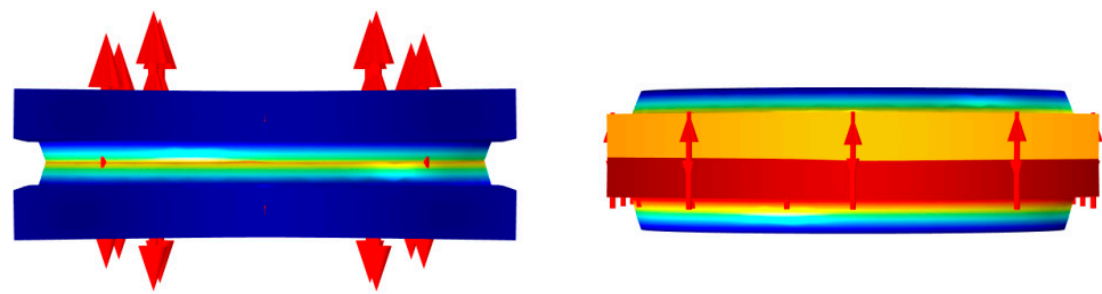

Figure 16. Vibration displacement diagram of "cavity cave" end point.

\section{Conclusions and Prospect}

The phononic crystals plate thickness exerts only a weak effect on the upper edge of the complete band gap, but it has a strong effect on the lower edge. As the thickness of the plate is increased, 
a nonlinear increase is observed with a gradually decreasing slope, and the increase in amplitude is not large-it increases by only approximately $10 \mathrm{~Hz}$ as the plate thickness is increased from 10 to $30 \mathrm{~mm}$. In terms of the directional band gap, the largest change is the fourth directional band gap at the 6-7 band position, and the modes are the scatterer vibrating along the $x$-axis and the matrix vibrating along the z-axis. The lower edge of the band gap is the same, but the upper edge of the band gap and lower edge of the full band gap exhibit consistent nonlinear growth with a gradually decreasing slope, although the growth amplitude is large, increasing by approximately $343 \mathrm{~Hz}$ as the plate thickness is increased from 10 to $30 \mathrm{~mm}$. These changes and characteristics can be observed intuitively in the comparison analysis band diagram.

Phononic crystals cavity plates greatly improves STL in the frequency domain beyond the start of the band gap. The average STL of the phononic crystals cavity plates is greatly superior to that of the phononic crystals plate, and the peak value is $100 \mathrm{~dB}$, which represents an increase of more than $30 \mathrm{~dB}$ over the corresponding values for the phononic crystals plate of various thicknesses. Furthermore, a cavity-like "cavity cave" appears near the first attenuation peak in the STL diagram. Because "cavity cave" is accompanied by the appearance of the cavity and its changes do not depend only on changes in the cavity, the formation mechanism of the "cavity cave" is determined from the difference between the phononic crystals plate and gas-acoustic coupling in the cavity.

Reducing the scatterer radius $r$ causes the phononic crystals plate and phononic crystals cavity plates to exhibit a nonlinear decrease at the same slope with a gradually decreasing slope, which is near the average of the three phononic crystals plates with different thicknesses. The difference is that the extreme value for the phononic crystals cavity plates is greatly improved compared to that for the phononic crystals plate of all thicknesses, and subject to all values of $r$. The overall trend in the STL image compared with that for the ordinary phononic crystals plate exhibits a significant upward phenomenon, indicating that the cavity structure of the phononic crystals cavity plates results in considerably improved noise reduction performance.

With an increase in cavity thickness, the position of the STL peak of the phononic crystals cavity plates is unchanged. However, both the extreme and average STL values increase nonlinearly with a decreasing slope. The width of the "cavity cave" gradually decreases, and its decrease means an increase in the average STL. Therefore, the larger the cavity within a certain limit, the better the sound insulation effect of the phononic crystals cavity plates. After a certain limit is exceeded, the benefits clearly disappear.

As the thickness of the plate is increased, the average STL gradually increases, and the position of the STL peak gradually moves toward higher frequencies whereas the extreme value increases nonlinearly with a decreasing slope. The width of the "cavity cave" gradually decreases as the thickness of the plate is increased, and it decreases as the starting and end frequencies of the "cavity cave" closer, with the rate of decrease becoming lower. This decrease in the "cavity cave" width means that the average STL increases. Therefore, the larger the plate thickness, within a certain limit, the better the sound insulation effect of the phononic crystals cavity plates.

Although the existence of "cavity cave" seems to be due to the appearance of cavity structure, it is actually caused by the coupling of the cavity and phononic crystals plate. The mechanism is such that at the starting point of the corresponding band gap, the phononic crystals plate increases the transmission efficiency of sound because of the opposite phase vibration of the scatterer or matrix located on the two sides of the cavity. Therefore, changes to the "cavity cave" are inseparably related to plate thickness and cavity thickness. Further research can be done in the future. It can be foreseen that mastering the mechanism and law in the "cavity cave" could be essential for enabling the application and development of phononic crystals cavity plates in the field of noise reduction.

Author Contributions: C.C. provided ideas and solutions, Z.G. established a simulation model and wrote an article, S.L., H.F. and C.Q. participated in the simulation experiment and wrote an article. All authors have read and agreed to the published version of the manuscript. 
Funding: This research was funded by "the Fundamental Research Funds for the Central Universities", grant number 2018QN087" and "Study on main equipment sound source model and plant boundary noise prediction technology for UHV substations", grant number GYW17201900046.

Conflicts of Interest: The authors declare no conflict of interest.

\section{References}

1. Goffaux, C.; Vigneron, J.P. Theoretical study of a tunable phononic band gap system. Phys. Rev. B 2001, 64, 075118. [CrossRef]

2. Wen, J.; Zhao, H.; Lv, L.; Yuan, B.; Wang, G.; Wen, X. Effects of locally resonant modes on underwater sound absorption in viscoelastic materials. J. Acoust. Soc. Am. 2011, 130, 1201-1208. [CrossRef] [PubMed]

3. Gao, J.; Zou, X.-Y.; Cheng, J.-C.; Li, B. Band gaps of lower-order Lamb wave in thin plate with one-dimensional phononic crystal layer: Effect of substrate. Appl. Phys. Lett. 2008, 92, 023510. [CrossRef]

4. Sigalas, M.; Economou, E. Elastic and acoustic wave band structure. J. Sound Vib. 1992, 158, 377-382. [CrossRef]

5. Kushwaha, M.S.; Halevi, P.; Dobrzynski, L.; Djafari-Rouhani, B. Acoustic band structure of periodic elastic composites. Phys. Rev. Lett. 1993, 71, 2022-2025. [CrossRef] [PubMed]

6. Kushwaha, M.S.; Halevi, P.; Martínez, G.; Dobrzynski, L.; Djafari-Rouhani, B. Theory of acoustic band structure of periodic elastic composites. Phys. Rev. B 1994, 49, 2313. [CrossRef] [PubMed]

7. Wang, X.P.; Jiang, P.; Chen, T.N.; Yu, K.P. Frequency characteristics of defect states in a two-dimensional phononic crystal with slit structure. Int. J. Mod. Phys. B 2016, 30, 1650025. [CrossRef]

8. Shi, X.; Shu, H.; Zhu, J.; Wang, X.; Dong, L.; Zhao, L.; Liang, S.; Liu, R. Research on wave bandgaps inacircular plate of radial phononic crystal. Int. J. Mod. Phys. B 2016, 30, 1650162. [CrossRef]

9. Gao, N.; Wu, J.H.; Yu, L. Large band gaps in two-dimensional phononic crystals with self-similarity structure. Int. J. Mod. Phys. B 2015, 29, 1550017. [CrossRef]

10. Martínez-Sala, R.; Sancho, J.; Sánchez, J.V.; Gómez, V.; Llinares, J.; Meseguer, F. Sound attenuation by sculpture. Nature 1995, 378, 241. [CrossRef]

11. Liu, Z.; Zhang, X.; Mao, Y.; Zhu, Y.Y.; Yang, Z.; Chan, C.T.; Sheng, P. Locally resonant sonic materials. Science 2000, 289, 1734-1736. [CrossRef]

12. Liu, Z.; Chan, C.T.; Sheng, P. Analytic model of phononic crystals with local resonances. Phys. Rev. B 2005, 71, 014103. [CrossRef]

13. Goffaux, C.; Sánchez-Dehesa, J. Two-dimensional phononic crystals studied using a variational method: Application to lattices of locally resonant materials. Phys. Rev. B 2003, 67, 144-301. [CrossRef]

14. Steurer, W.; Sutter-Widmer, D. Photonic and phononic quasicrystals. J. Phys. D: Appl. Phys. 2007, 40, R229-R247. [CrossRef]

15. Vasseur, J.O.; Deymier, P.A.; Chenni, B.; Djafari-Rouhani, B.; Dobrzynski, L.; Prevost, D. Experimental and theoretical evidence for the existence of absolute acoustic band gaps in two-dimensional solid phononic crystals. Phys. Rev. Lett. 2001, 86, 3012. [CrossRef]

16. Jensen, J. Phononic band gaps and vibrations in one- and two-dimensional mass-spring structures. J. Sound Vib. 2003, 266, 1053-1078. [CrossRef]

17. Sigmund, O.; Jensen, J.S. Systematic design of phononic band-gap materials and structures by topology optimization. Philos. Trans. R. Soc. A Math. Phys. Eng. Sci. 2003, 361, 1001-1019. [CrossRef] [PubMed]

18. Yu, J.-K.; Mitrovic, S.; Tham, D.; Varghese, J.; Heath, J.R. Reduction of thermal conductivity in phononic nanomesh structures. Nat. Nanotechnol. 2010, 5, 718-721. [CrossRef] [PubMed]

19. Alegre, T.P.M.; Safavi-Naeini, A.H.; Winger, M.; Painter, O. Full phononic bandgap in 2D-optomechanical crystals. In CLEO: Science and Innovations; Optical Society of America: Washington, DC, USA, 2011.

20. Graczykowski, B.; Vogel, N.; Bley, K.; Butt, H.-J.; Fytas, G. Multiband Hypersound Filtering in Two-Dimensional Colloidal Crystals: Adhesion, Resonances, and Periodicity. Nano Lett. 2020, 20, 1883-1889. [CrossRef]

21. Yang, S.; Page, J.H.; Liu, Z.; Cowan, M.L.; Chan, C.T.; Sheng, P. Focusing of Sound in a 3D Phononic Crystal. Phys. Rev. Lett. 2004, 93, 024301. [CrossRef] 
22. Alonso-Redondo, E.; Schmitt, M.; Urbach, Z.; Hui, C.M.; Sainidou, R.; Rembert, P.; Matyjaszewski, K.; Bockstaller, M.R.; Fytas, G. A new class of tunable hypersonic phononic crystals based on polymer-tethered colloids. Nat. Commun. 2015, 6, 1-8. [CrossRef]

23. Lin, J.; Lin, S. Study on a Large-Scale Three-Dimensional Ultrasonic Plastic Welding Vibration System Based on a Quasi-Periodic Phononic Crystal Structure. Crystals 2020, 10, 21. [CrossRef]

24. Hussein, M.I.; Frazier, M.J. Damped phononic crystals and acoustic metamaterials. In Acoustic Metamaterials and Phononic Crystals; Springer: Berlin/Heidelberg, Germany, 2013; pp. 201-215.

25. Dong, Y.; Yao, H.; Du, J.; Zhao, J.; Chao, D.; Wang, B. Research on low-frequency band gap property of a hybrid phononic crystal. Mod. Phys. Lett. B 2018, 32, 1850165. [CrossRef]

26. Zhou, X.; Xu, Y.; Liu, Y.; Lv, L.; Peng, F.; Wang, L. Extending and lowering band gaps by multilayered locally resonant phononic crystals. Appl. Acoust. 2018, 133, 97-106. [CrossRef]

27. Li, Y.F.; Meng, F.; Li, S.; Jia, B.; Zhou, S.; Huang, X. Designing broad phononic band gaps for in-plane modes. Phys. Lett. A 2018, 382, 679-684. [CrossRef]

28. Zuo, S.; Huang, H.; Wu, X.; Zhang, M.; Ni, T. Low-frequency band gap of locally resonant phononic crystals with a dual-base plate. J. Acoust. Soc. Am. 2018, 143, 1326-1332. [CrossRef]

29. Jia, Z.; Chen, Y.; Yang, H.; Wang, L. Designing Phononic Crystals with Wide and Robust Band Gaps. Phys. Rev. Appl. 2018, 9, 044021. [CrossRef]

30. Anvariyeh, F.S.; Jalili, M.; Fotuhi, A.R. Nonlinear vibration analysis of a circular plate-cavity system. J. Braz. Soc. Mech. Sci. Eng. 2019, 41, 66. [CrossRef]

31. Dowell, E.H. Transmission of Noise from a Turbulent Boundary Layer through a Flexible Plate into a Closed Cavity. J. Acoust. Soc. Am. 1969, 46, 238-252. [CrossRef]

32. Qaisi, M.I. Free vibrations of a rectangular plate-cavity system. Appl. Acoust. 1988, 24, 49-61. [CrossRef]

33. Frampton, K.D.; Clark, R.L. Sound transmission through an aeroelastic plate into a cavity. AIAA J. 1997, 35, 1113-1118. [CrossRef]

34. Zhang, H.; Shi, D.; Zha, S.; Wang, Q. Vibro-acoustic analysis of the thin laminated rectangular plate-cavity coupling system. Compos. Struct. 2018, 189, 570-585. [CrossRef]

35. Sarıül, A.S.; Karagözlü, E. Vibro-acoustic coupling in composite plate-cavity systems. J. Vib. Control. 2018, 11, 2274-2283. [CrossRef]

36. Xin, F.X.; Lu, T.J.; Chen, C. Sound Transmission Through Simply Supported Finite Double-Panel Partitions With Enclosed Air Cavity. J. Vib. Acoust. 2010, 132, 011008. [CrossRef]

37. Muzar, E.; Aval, G.A.; Stotz, J.A.H. Wet-etched phononic crystal waveguiding on GaAs. J. Phys. D Appl. Phys. 2018, 51, 044001. [CrossRef]

38. Wang, Y.-F.; Wang, Y.-S.; Wang, L. Two-dimensional ternary locally resonant phononic crystals with a comblike coating. J. Phys. D Appl. Phys. 2013, 47, 015502. [CrossRef]

39. Peiffer, A.; Grunewald, M.; Lempereur, P. Comment on “A lightweight yet sound-proof honeycomb acoustic metamaterial" [Appl. Phys. Lett. 106, 171905 (2015)]. Appl. Phys. Lett. 2015, 107, 216101. [CrossRef]

Publisher's Note: MDPI stays neutral with regard to jurisdictional claims in published maps and institutional affiliations.

(C) 2020 by the authors. Licensee MDPI, Basel, Switzerland. This article is an open access article distributed under the terms and conditions of the Creative Commons Attribution (CC BY) license (http://creativecommons.org/licenses/by/4.0/). 